Editor Christos Ballas, MD

Department of Psychiatry, University of Pennsylvania,

3535 Market Street, 2nd Floor, Philadelphia, PA 19104, USA.

E-mail: christosballas@yahoo.com

Contributor Paul Ballas, DO

Department of Psychiatry, Thomas Jefferson University Hospital,

833 Chestnut Street, Suite 210, Philadelphia, PA 19107, USA.

E-mail: paulballas@yahoo.com

\title{
The National Child Traumatic Stress Network
}

http://www.nctsn.org

This organization was created by Congress in 2000 to improve the care of children exposed to traumatic events. It is a collaboration of many organizations that was created to develop evidencebased resources for health care providers and the public. The "CTS Intro" section provides several online essays on childhood trauma and stress, including the free brochure "Understanding Child Traumatic Stress" (available in PDF format), which provides information in language accessible to nonclinicians. The "Trauma Types" section provides short descriptions of various topics related to childhood trauma, including "Medical Trauma," "Terrorism," and "School Violence \& Crises." Of note is the "Pediatric Medical Trauma Stress Toolkit for Health Care Providers" in the "Medical Trauma" area. It provides several documents available for download for families and health care providers and offers specific recommendations for screening for trauma symptoms in the medically ill child. Additional information is available in the "Resources" section, and many of the documents on the website are available in Spanish.

\section{Learning Disorders Online}

http://www.ldonline.org

This website was designed as a national education service of WETA-TV, the PBS affiliate in Washington, DC. It contains information on assessing and treating several learning disorders (LDs). The "Getting Started" section contains an online essay about LDs, attention-deficit/hyperactivity disorder, and a glossary of terms frequently encountered by patients and their families when they seek treatment. The "LD Topics" section features many online essays, including "Gifted \& LD," "IEPs," and "Nonverbal LDs." Each area contains articles, question-and-answer sections, and recommendations of books and relevant websites.

The "Multimedia" section contains videos on LDs. The "Especially For ..." section has information targeted to educators, parents, and children. The "Educators" area contains several articles of interest to teachers, such as instructional strategies for teaching children with LDs. The "Parents" area offers articles on identifying LDs, special education requirements, and learning support at home. This website also has a "Finding Help" area that contains listings of LD resources and an "LD Online Yellow Pages," which presents a directory of professionals and schools that can be searched by street address.

\section{CureSearch National Childhood Cancer Foundation}

http://www.nccf.org

This organization is devoted to raising funds for fighting childhood cancer. Several resources on this website may be of interest to families coping with the diagnosis of cancer in a child. The "For Parents/Families" section provides information on a variety of pertinent topics in areas such as "Impact on the Patient," "School Issues," and "Impact on the Family." Of note is the area "Navigating the Healthcare System," which may be a useful resource to be introduced to families when the cancer diagnosis is first made, as it provides articles on the function of members of the health care team and insurance issues. This area also contains a handbook on childhood cancer 
and its treatments that is available in English, Spanish, and French. The "For Patients" section has several areas with information on coping with cancer, organized by "Newly Diagnosed," "In Treatment," "End of Treatment," and "After Treatment." Essays available in the section are individualized by an online tool in which the user enters the type of cancer and child's age.

\section{MayoClinic.com Mental Health Center}

http://www.mayoclinic.com/health/mental-health/MH99999

This is the section of the Mayo Clinic's website that contains information on diagnosing and treating psychiatric disorders. The front page provides a "Find It FAST" list, which lists most major psychiatric disorders, from alcoholism to schizophrenia. These articles contain information on symptoms, causes, risk factors, and other aspects of the illnesses they describe and a "Lifestyle and Home Remedies" area that suggests steps people can take to improve their condition. The "Mental Health Awareness" area on the front page presents information on more general topics, such as "Mental Health vs. Mental Illness," "Impulse Control Disorders," and "Personality Disorders." The website also offers a "Mental Health Self-Care" section that lists tips on improving overall mental health. For example, the "Mood and Outlook" section has articles on self-esteem, resilience, weight loss, and stress during the holidays. 